\title{
Pyramid Prophecy
}

$\mathrm{TT}$ is now ten years since Mr. David Davidson published his first book on prophecy made from the measurements of the Great Pyramid of Gizeh. That book is now in its fifth edition, and has been followed by eight smaller publications, all of which have been given wide publicity in the public Press, through full-page advertisements and otherwise.

The latest pamphlet, a quarto of seventy pages, is entitled "The Hidden Truth in Myth and Ritual and in the Common Culture Pattern of Ancient Metrology" (Leeds : The Author, 47 Park Square ; London: Williams and Norgate, Ltd., 1934. $2 s$. 6d.) ; and metrologically the chief contention is that the various systems of measures in the ancient world were all derived from one system invented "to form a standard basis of reference for the many loosely formulated primitive systems of measures". If this were the case it is an important discovery. But unfortunately we stumble immediately against an astonishing series of statements, such as the following: "Surely, however, a 'widespread . . . diffusion of customs and institutions' necessarily implies widespread com. mercial intercourse; and does not the latter postulate the need for a standard system of measures as a common basis for exchange and barter?" It seems strange that such a-sentence could ever have been written in a world where the pound and the dollar fluctuate as they do, and the metric system has not yet been adopted by the English-speaking countries.

The essential point is that all primitive measures were based on a 'primitive inch' invented by $\mathrm{Mr}$. Davidson and equal in length to 1.0011 British inch. The method by which this is proved is interesting. A passage in Horapollo ("Hieroglyphics", 1, 5) reads : "To represent the current year they (i.e., the Egyptians) depict the fourth part of an aroura; now the aroura is a measure of land of an hundred cubits. And when they would express a year they say a quarter." Mr. Davidson states that the reason why the quarter-aroura represented the year was that its circumference, if circular, would be equal to 3652.42 of the primitive inches which he has invented. This is taken to prove the existence of the primitive inch; and Sir Flinders Petrie is rebuked in heavy type for refusing to believe it.

Actually, however, Mr. Davidson is demonstrably wrong. The meaning of the passage in Horapollo is this: The Egyptian word for the quarter-aroura is $h s b$; and in classical Egyptian the word for the current year is spelt ha.t-sp, where $a$ represents alif, and $t$ is the feminine ending which was dropped in pronunciation in the third millennium. This word ha.t occurs in Coptic as ha- or hi-. Horapollo plainly means that in his time the two words $h s b$ and $h a \cdot t-s p$ were pronounced the same; and all exponents of Egyptian morphology will support this explanation.

The point, however, on which $\mathrm{Mr}$. Davidson lays greatest stress is the pyramid's "Displacement Factor". This is derived from his theory (for which there is no evidence) that the pyramid in building fell short of its intended measurements, by an error. Of the most accurately built ancient building in the whole world this is impossible to believe. It is further stated that in consequence of this error the pyramid was left incomplete at its top platform, as it was found that the apexpyramid or cap-piece was too big to fit. There is, of course, no evidence of the existence of this cappiece ; and it is incredible that Khufu would have left his pyramid incomplete because the original cap-piece did not fit. He would simply have ordered a new one.

The error is said to have happened thus. Fairly early in building, the few casing-blocks that survive were laid in the middle of each side to guide the workmen. Of those that were added later, and have perished, Mr. Davidson says that they tapered until at the corners they were only half the correct thickness. Now this could never have happened by mistake; for the stones would not have fitted unless they were specially graduated; and that it did not happen has been shown by Sir Flinders Petrie ("Pyramids and Temples of Gizeh", p. 84) : "On all the casing, and on the core on which the casing fitted, there are lines drawn on the horizontal surfaces, showing where each stone was to be placed on the one below it. If the stones were merely trimmed to fit each other as the building went on, there would be no need to have so carefully marked the place of each block in this particular way." These points, with the corner sockets, prove that the casing was deliberately planned and there can have been no error. The "Displacement Factor" therefore falls to the ground.

Naturally we begin to ask: Why should the Great Pyramid demonstrate the fate of Britain and the Lost Tribes when it has no connexion with either? Mr. Davidson makes the connexion by inventing "Proto-Hebrews" who are said to have instructed the Egyptians in the building. There is no evidence for them ; but that does not, of course, influence the belief of Mr. Davidson and his followers in them. 
Anyone who may still wonder whether Mr. Davidson's book actually explains a divine revelalation should open the volume at random; he will find endless numerological jugglings and fictitious lines drawn in the pyramid. What Divine Being ever conceived descended to such puerilities? Truth, on the other hand, is known by its simplicity. For Christians the Bible is good enough, without seeking for guidance in the structure of the Great Pyramid. But since Mr. Davidson quotes from the Bible in support of his theories, it is quite fair to quote against him from St. Mark's Gospel, xiii, 22: "For there shall arise false Christs and false prophets, and shall shew signs and wonders, that they may lead astray, if possible, the elect."

Rupert Gleadow.

\section{Modern Street Lighting}

$\mathrm{I}^{\mathrm{N}}$ his presidential address to the Junior Institution of Engineers delivered on December 14, Mr. C. C. Paterson chose as his subject "Modern Street Lighting", laying stress on the necessity of making roads safe for traffic. It is important to remember that the number of licensed road vehicles in Great Britain has more than doubled during the last ten years. Even with the reduced maximum speed of 30 miles an hour in street lighted areas, good illumination is required for safe driving during night time. The great source of danger is that the eye has to function in conditions in which there is so little light. The eye sees by contrast either of colour or brightness. If everything were of the same colour and uniformly bright, and the visibility of the atmosphere were perfect, it would be impossible to distinguish objects from their backgrounds as there would be no contrast.

The illumination produced by bright sunshine is of the order of 8,000 foot-candles. On an overcast day, daylight falls from about 700 f.c. to 100 f.c. just before dusk. About half an hour after the sun sets, the illumination is about 5 f.c. At this point a number of drivers switch on their lights, and about ten minutes later when the illumination is 2 f.c. about 60 per cent of the cars have their lights on. When the illumination falls to 1 f.c. seeing is bad and car sidelights are beginning to glare. As the light falls to $0 \cdot 1$ f.c. the contrasts which give such good discrimination in full day. light are very slight, and the elements of the retina which give us the sensation of colour are weakening in their action. A man with a brown jacket and grey trousers now appears to have clothes of a uniform dark colour, but we are unable to say what colour it is. The dark grey lorry which can be seen clearly by daylight against a somewhat lighter grey road surface now disappears, as the contrast is not sufficient.

The problem of good street lighting is to find how to make the contrasts sufficiently distinct. For good seeing, the maxim is to make contrasts as distinct as possible, and this leads to the simple rule "make the road surface as bright as possible". Street lamps from this point of view should not be designed to light up objects on the road, but the road itself. Objects on the street are usually seen as dark things against a bright background, and this is the effect which street lighting should enhance. It is often true that when we drive behind a motor headlight, we see because its horizontal beam lights up the object itself rather than the road. But this projector beam is $20-30$ thousand foot-candles, which is many times greater than would be possible under good street lighting conditions. For general street lighting, it would, taking expense into account, be impossible to make the objects brighter than the street.

The first step towards improving lighting is to make the road form a light background by means of its polish or shiny nature. Light can be directed on to the road in such a way that it reflects like a mirror. It does this when the light is directed along the road instead of on it. It is surprising what unpromising materials reflect light in this way. An asphalt road surface well polished by traffic reflects light excellently. A rough non-skid road surface does so also in a less degree. It is the same kind of effect as that produced by the moon when it shines towards us over water. Fortunately, as roads are at present surfaced, the conditions are often ideal for securing an uninterrupted bright path of light along their whole length. For an expenditure of three watts per foot run of road, we can obtain an illumination of 0.5 f.c. as seen on a white surface.

The two guiding principles used in modern street lighting are increasing the road brightness by specular (mirror) reflexion and increasing it by diffuse reflexion. The modern designer uses street illumination only as a rough guide to find the total amount of light available in the street. It is little use to specify road lighting by means of the 'minimum' illumination produced. Judging, as is usually done, the relative merits of two systems of lighting by the 'minimum' illumination produced is sometimes quite misleading. The real criterion is to find out which yields the highest road brightness with a given street surface condition.

If a road is so wet as to be like a still sheet of 